\title{
Experimental Study of Industrial Waste in CSCE Block
}

\author{
${ }^{* 1}$ Vaishali Rajurkar, ${ }^{2}$ Dr. Anil Chitade \\ ${ }^{1}$ Shri Ramdeobaba College of Engineering and Management, Nagpur \\ ${ }^{2}$ Gondwana University, Gadchiroli \\ Email: ${ }^{1}$ rajurkarvj@rknec.edu, ${ }^{2}$ a.chitade@gmail.com
}

Received: 06th November 2019, Accepted: 20th November 2019, Published: 31st December 2019

\begin{abstract}
In recent years innovations in technology and increasing demand of materials in construction industry have led to the exploitation of natural resources. Also due to rapid industrialization a huge amount of waste is generated which creates several problem on environment, the safe disposal and reuse of such waste is a major concerned. In this study, the effective and optimum use of such waste to replace natural sand is studied. On the other hand day by day increase in temperature to climate change increases the operational cost of a building to overcome such situation natural soil can be use as an ideal construction material, which has potential to reduce carbon footprint. In this study locally available non swelling soil is selected for investigation. Cement stabilised compressed earth (CSCE) blocks are prepared at varying percentage of demolishing waste (DW) to replace natural sand and Fly Ash (FA) to improve strength property of block. The optimum percentage of DW with soil is investigated. Optimum combination obtained further studied for effect of FA. The cube compressive strength and secant modules is varying with fly ash content and curing period, there is negligible deviation in dry density mostly within $10 \%$ of FA. Due to pozolonic effect cube compressive strength increases with increase of FA up to $10 \%$. Further increase in fly ash reduces density of material and ultimately strength of CSCE blocks.
\end{abstract}

\section{Keywords}

Cement Stabilized Compressed Earth Block; Non Swelling Soil; Fly Ash; Cube Compressive Strength; Initial Tangent Modulus

\section{Introduction}

In recent year, rapid urbanisation and infrastructural development all over the world which required energy in their manufacturing and transportation process. The construction material like cement, steel etc. requires huge amount of energy and produce high level of greenhouse gas. Especially the modern infrastructures are energy intensive and produce massive carbon dioxide [20]. To fulfil the day by demand of construction industry, large amount of material like sand and aggregate are required, cause exploitation of natural resources results to scarcity of building materials. Therefore the replacement of such courser material by the material which can be waste product of different industries such as granulated blast furnace slag, mine tailings, demolishing waste etc is required. Recycling and reuse is the another important key concerned for sustainable development. As it is well known, Thermal power plants produces ample quantity of fly ash which is in suspended form due to its low density, in atmosphere causing irreversible environmental harm. Construction industry is the biggest industry which utilises fly ash as a replacement of cement by supplementary cementing material has to be utilized in construction industry.

The country like India soil is available abundantly which can be utilised as construction material due to its number of benefits. Rammed earth is the ancient and most widely used construction technology in human history, and more popularly used in all over the world for hundreds to thousands of years [15,14]. The raw material required for the construction is locally available which save the cost of transportation of raw material. Rammed earth construction technique is used for wall and other building units like blocks, bricks, paver blocks etc. Rammed-earth constructions are simple to construct, non combustible, thermally massive, strong, and durable. The technique is based on, compressing the processed soil to achieve required density of block. The soil may stabilised or un-stabilised is compacted in progressive layers in formwork or in mould. Soil used for the construction should well graded loamy soil with optimum clay content leading to maximum strength is in the range of $14-16 \%$ [4]. Red soil is often preferable for such construction due to its strength, non swelling characteristics and good appetence. In this earth is stabilised with small amount of lime or cement with the aim of improving their mechanical resistance and durability [14,15]. The compressed soils are energy efficient and the embodied energy of buildings using these technologies is less than half of the energy consumed by conventional buildings [4,5]. The present study is aimed at understanding the influence of granular material on strength properties of cement stabilized earth blocks also the effect of fly ash on the soil-cement block characteristics. 


\section{Materials and Methods \\ Soil}

A locally available non swelling red soil is collected from site, after performing the wet sieve analysis sand content is found to be $15 \%$.The most important is clay content, optimum clay content leading to maximum strength is in the range of 14-16\%; [7] which is observed as $13 \%$,. The other physical properties of the soils are determined according to Indian Soil Classification System (IS: 1498, 1970). Specific gravity of soil 2.25, Liquid limit and plasticity index for the soil are 34 and 5.7\%, respectively, soil is designated as ML as per IS classification system is preferable. The soil is found to be non swelling and pusses low plasticity property. Maximum dry density of the soil is obtained to be $16.8 \mathrm{kN} / \mathrm{m}^{3}$ from Standard Proctor test, the strength gaining parameter is dry density of soil referring to the study by B.V. Venkatarama Reddy dry density should be within the range of 17 to $18 \mathrm{kN} / \mathrm{m}^{3}$.

\section{Demolishing Waste}

Brick and mortar were collected from construction site at Nagpur. It is crushed by rammer and the fraction passing through $10 \mathrm{~mm}$ and retained on 75 micron IS sieve, is considered as replacement of natural sand was used as a secondary material added to the base soils in the investigation. The courser particles are within the range of medium to fine size and well graded in nature. The specific gravity the material is 2.4 .

Fly Ash

In the present study fly ash is collected in dry state from Koradi thermal power plant, Koradi, Nagpur, India.

An ordinary Portland cement of 43 grade was used as a binding material. This type of cement should confirm according to IS: 8112-1989. Minimum compressive strength requirements for the blocks readily achieved using soils, stabilized with 5-10\% cement,[3] Optimum strength both wet and dry is reached when for $8 \%$ cement [5].Therefore optimized the $8 \%$ cement of base material as a stabilizer for all soil mixes.[3].Specific gravity of FA is 2.0 .

\section{Experimental Programme \\ Reconstituted Soil}

As there is a lack of granular material in the original soil, and pertaining to efficient utilization of materials and resources, natural sand is replaced by recycled demolished building wastes, which have different percentage of sand silt and clay. The prepared soil mix has been designated as M1, M2, M3, M4 and M5 (Table 1).

Rammed soil cement blocks stabilised with cement are manufactured by using above soil mix. As it is well known fact that dry density blocks greatly affects the strength of the block therefore dry density is kept constant and the range of it is 17 to $18 \mathrm{kN} / \mathrm{m}^{3}$. The size of is blocks decided as $100 \mathrm{X} 100 \mathrm{X} 100 \mathrm{~mm}$ for the investigation. Static compaction method of block making is become more efficient than dynamic compaction by means of falling weight impact on material [16,17]. But in this study dynamic Compaction method is used to get uniform compaction and ultimately the density of soil, processed soil is placed in three uniform layers and compacted as per IS 4332 Part.

The soil mixes are first mixed uniformly with cement in dry condition and optimum moisture content is added in soil. The prepared blocks are removed from mould are shown in figure 1. The blocks are further cured for 7 and 28 days in wet burlap.

\begin{tabular}{|c|c|c|c|c|c|}
\hline \multirow{2}{*}{$\begin{array}{l}\mathrm{Sr} \\
\dot{\mathrm{N}} \\
\mathrm{o} .\end{array}$} & \multirow{2}{*}{$\begin{array}{c}\text { Mix } \\
\text { desig } \\
\mathrm{n}\end{array}$} & \multicolumn{2}{|c|}{$\begin{array}{l}\text { Quantity Mix in \% } \\
\text { (With } 8 \% \text { Cement) }\end{array}$} & \multirow[t]{2}{*}{$\begin{array}{c}\text { OMC } \\
(\%)\end{array}$} & \multirow{2}{*}{$\begin{array}{c}\text { Dry } \\
\text { density } \\
\left(\mathrm{kN} / \mathrm{m}^{3}\right)\end{array}$} \\
\hline & & $\begin{array}{l}\text { Silt }+ \\
\text { Clay }\end{array}$ & $\begin{array}{l}\text { Dem. } \\
\text { Waste }\end{array}$ & & \\
\hline 1 & M1 & 60 & 40 & 17.24 & 17.5 \\
\hline 2 & M2 & 55 & 45 & 17.1 & 17.72 \\
\hline 3 & M3 & 50 & 50 & 16.89 & 17.9 \\
\hline 4 & M4 & 45 & 55 & 16.65 & 18.01 \\
\hline 5 & M5 & 40 & 60 & 16.50 & 18.22 \\
\hline
\end{tabular}

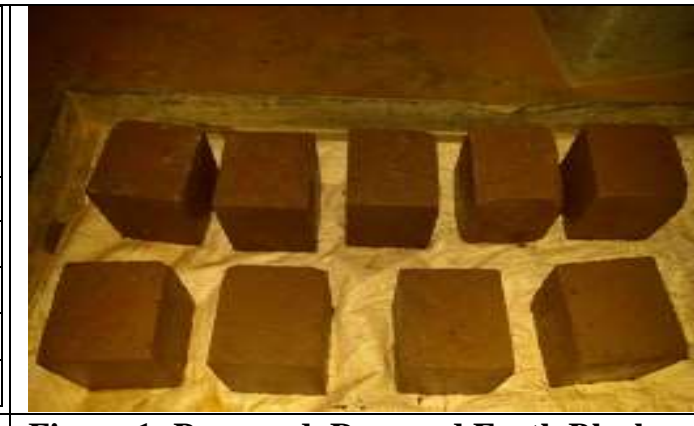

Table 1: Proportions of Soil Mixes and their Properties

Figure 1: Prepared Rammed Earth Blocks

\section{Test on Blocks and Reconstituted Soil}

Various properties of soil cement blocks and wet cube compressive strength is determined after 7 and 28 days. The cured samples are immersed in potable water for $48 \mathrm{hrs}$ and surface dry before testing as per IS code (1992). The blocks were placed in between two wooden plates, and tested in unconfined compression tester; the failure pattern of the block is shown in Figure 1.

The wet cube compressive strength of blocks and its stress strain behaviour is observed, the similar failure pattern of the maximum blocks are observed as shown in Figure 2 after 28 days of curing. 
The best results obtained from the above mixes are considered for further investigation, M4 and M5 mix are found satisfactory with respect to its density and strength. Thermal power plants generate solid wastes in bulk quantities, which are another pozzolanic material and used as a supplementary cementing material in soilcement mixture. FA is added in 5, 10, 15, and $20 \%$ by weight in M4 and M5 soil mixes and the cement percentage is curtailed to $1 \%$ of a total weight of mix to enhance their strength and to minimise the cost of stabiliser.

\section{Result and Discussion}

The wet cube compressive strength and stress strain behaviour is of blocks is shown in Figure 3. For specimen cured for 28 days showed higher compressive strength than 7 days cured specimen with similar behaviour in stress strain relationship and failure pattern is observed after 7 and 28 days curing. In case of block with $60 \%$ soil for M1 group wet compressive strength is $2.06 \mathrm{MPa}$ and it is $3.7 \mathrm{MPa}$ with $40 \%$ soil in M5 group As there is in increase in soil content reduces the strength, and maximum strength is achieved at higher courser material like sand. It is also observed that the density of blocks is increases with increase in granular content and ultimately the strength of earth blocks. But after certain percentage increase in courser material reduces the cohesion which makes the material heterogeneous which results in reduction in strength of blocks.

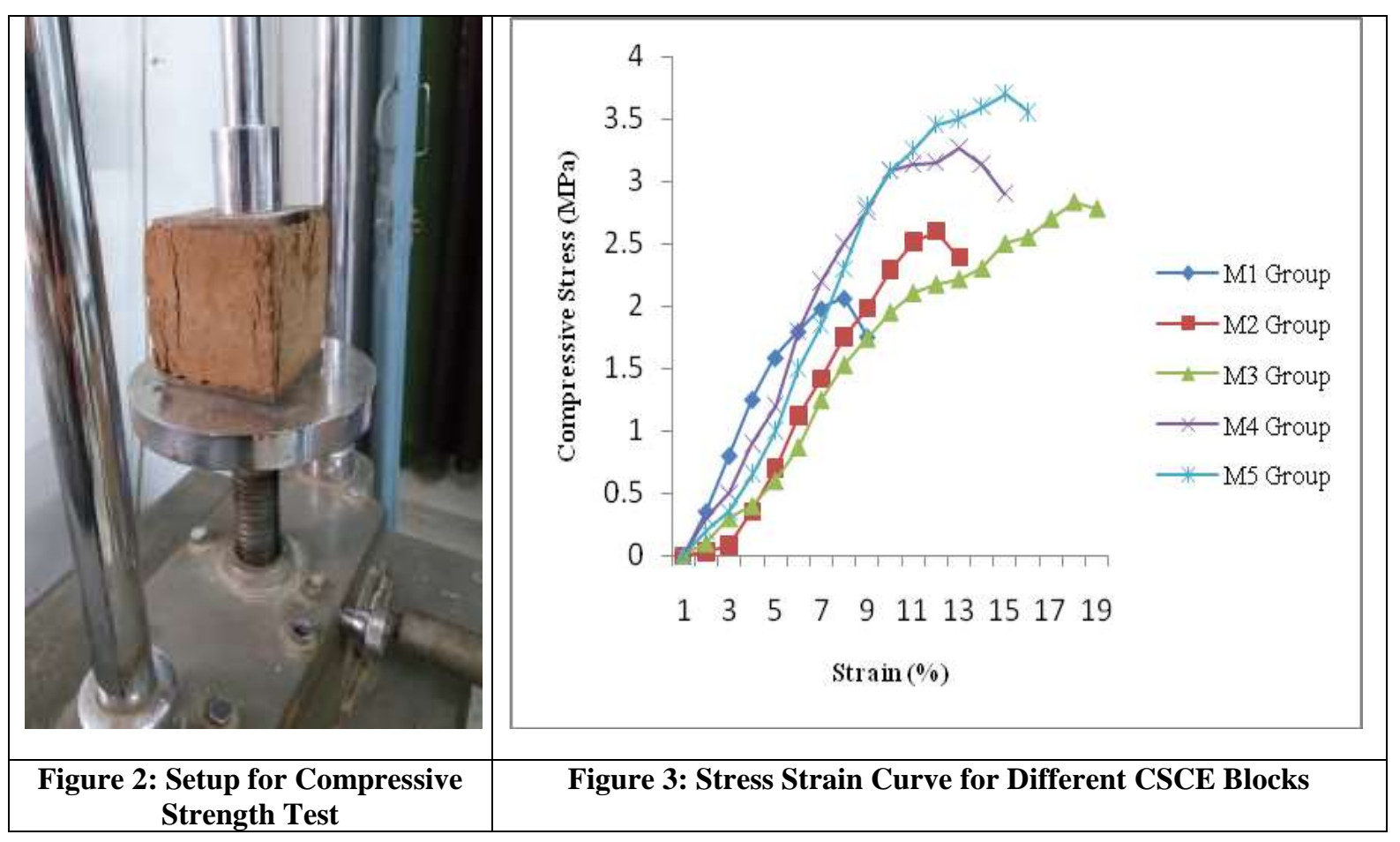

Wet compressive strength of modified soil cement blocks with addition of fly ash content is obtained after 28 days curing, stress strain curve of both M4 and M5 mixes shows similar behaviour as shown in Figure 4 and 5. Load bearing capacity of soil cement blocks increases with increase in FA content due to its pozzolonic effect, reaches a peak value at $15 \%$ of FA for $45 \%$ soil and $55 \%$ DW and drops further at 20\% FA. The same trend was observed in M5 group also peak value is attained at $10 \%$ FA for $40 \%$ soil and $60 \%$ FA and drop sharply at $15 \% \mathrm{FA}$ as shown in figure 5.

In case of $8 \%$ cement blocks the wet compressive strength is varies from $2.06 \mathrm{MPa}$ for $60 \%$ soil to $3.7 \mathrm{MPa}$ for $40 \%$ soil. At $7 \%$ cement and 10\% FA the strength is found to $4.35 \mathrm{MPa}$ for 40 soils in this combination wet strength is increased by nearly $18 \%$. Further increase in FA reduces the density of blocks which results in reduction in strength. Same trend is observed in M4 group for 55\% DW and $45 \%$ soil in this at $8 \%$ cement wet strength is $3.26 \mathrm{MPa}$ where as at $7 \%$ cement and $15 \% \mathrm{FA}$ it is found to be $4.13 \mathrm{MPa}$ which is $27 \%$ more than $8 \%$ cement. 


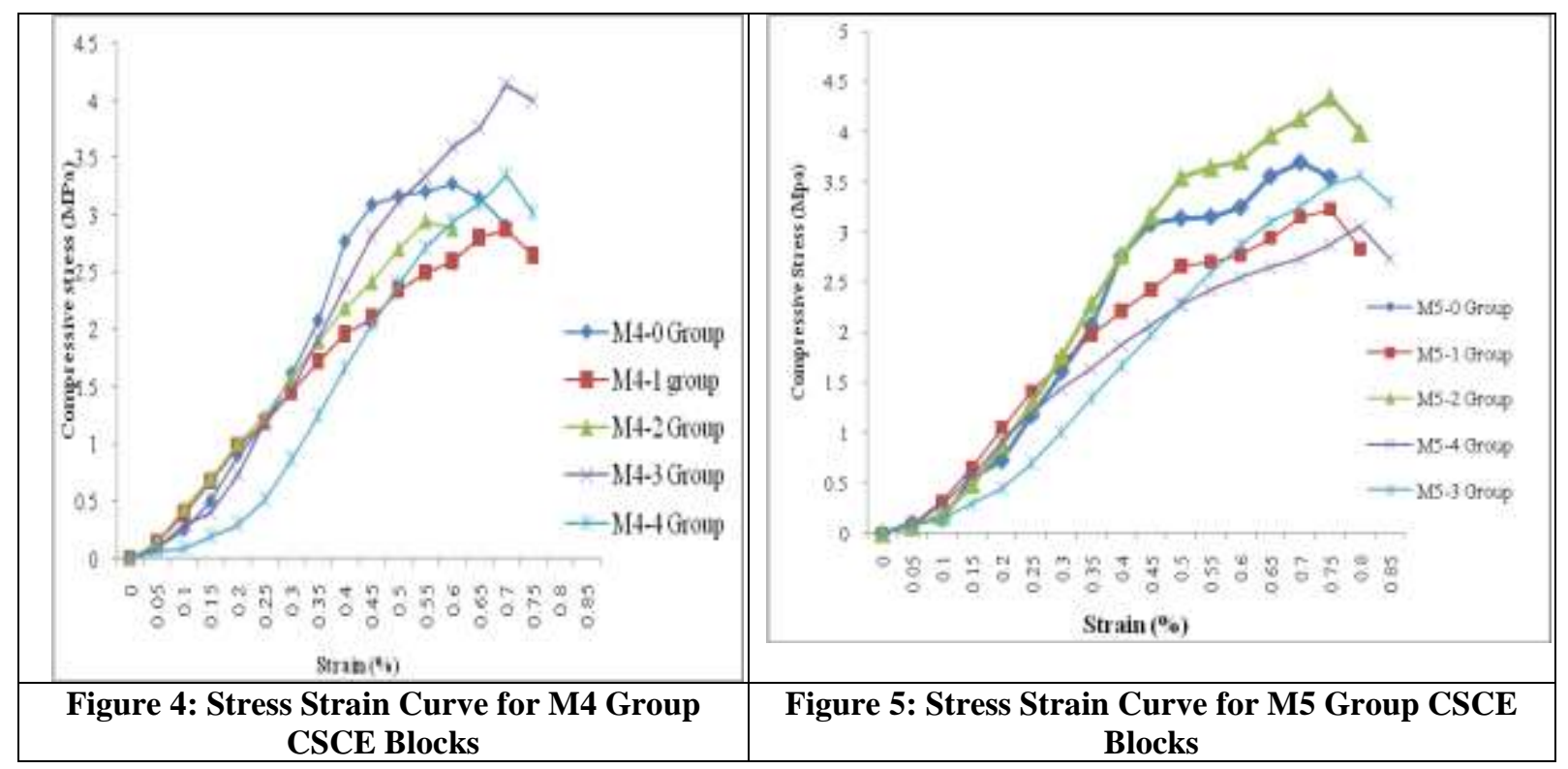

Wet compressive strength of modified soil cement blocks with M5 group is more in all percentage of FA as compared to M4 group; around 20 to $22 \%$ more strength is observed $60 \%$ DW and $40 \%$ soil. In M5 sample maximum strength is found at 10\% FA where as in M4 group it is observed at $15 \%$ of FA as shown in figure 6. In FA adhesion capacity is more as compared to soil so addition of it starts to bind soil particle close to each other and hence decrement in the voids of blocks, and decrement in voids ultimately increases its load carrying capacity. In M4 group amount of soil is more and hence more fines which increases the specific area therefore optimum results are obtained at 15\% FA; where as in M5 group soil content is less i.e.38 \% of total mix, therefore the optimum results are obtained at 10\% FA. The maximum strength in M5 group is $4.35 \mathrm{MPa}$ with $10 \%$ FA which is $21 \%$ more than M4 with $15 \%$ FA.

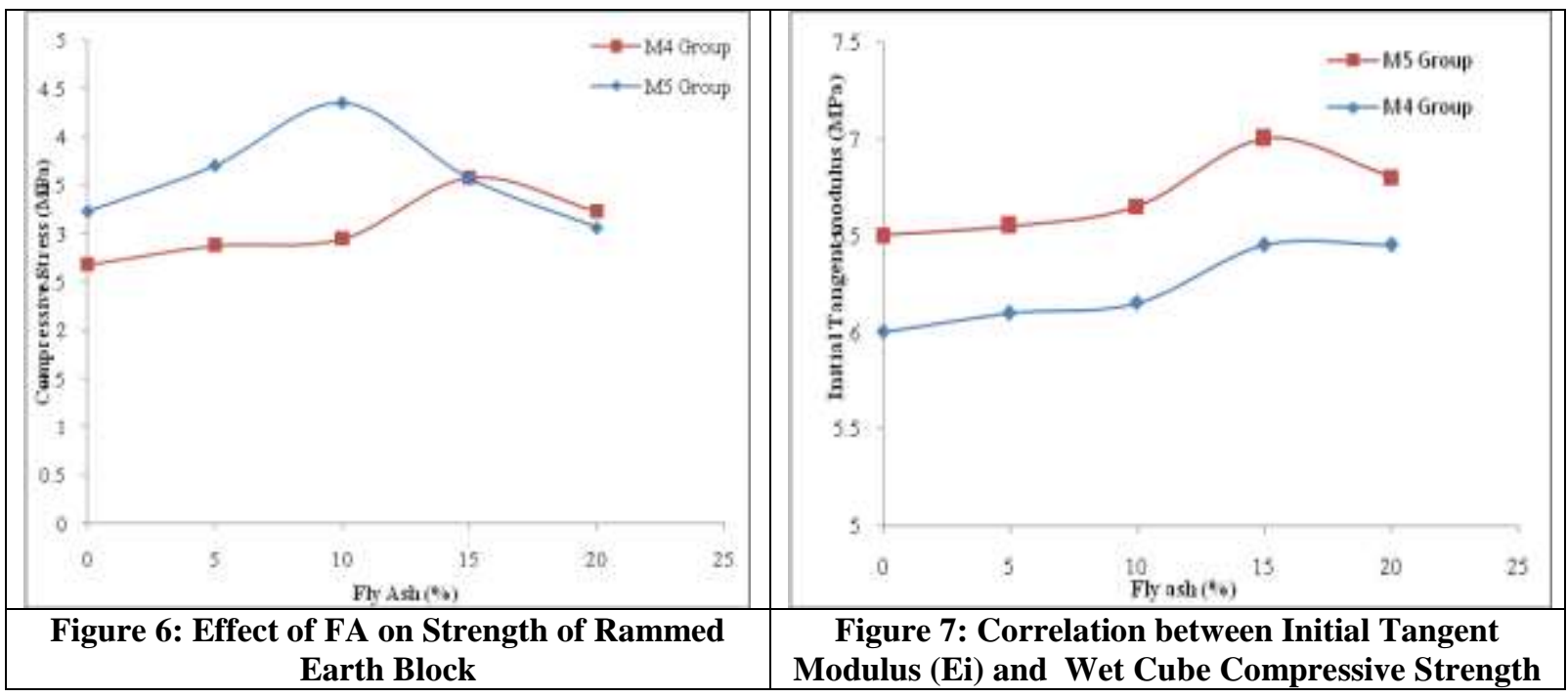

\section{Initial Tangent Modulus}

Initial tangent modulus (Ei) is an important parameter of the rammed earth material because it characterizes the stiffness of material. It is determined as the slope of the tangent line to the origin of the stress-strain curve. Higher compressive strength leads to the higher initial tangent modulus and ultimately the toughness of material and also increases post failure capacity of a material. It can be seen that the Ei values range from 4 to $8.5 \mathrm{MPa}$ in wet condition also it depends on the curing period.

Figure 8 shows the relation between Initial tangent modulus (Ei) and wet cube compressive strength (sc) for all rammed earth material specimen. The correlation between Ei and compressive strength is well fitted by a linear relation and can be expressed as $\mathrm{Ei}=1.249 \mathrm{sc}+2.238$ and the coefficient of correlation $\mathrm{R}^{2}$ is 0.86 . The Ei of M5 group is more as compared to M4 group. 


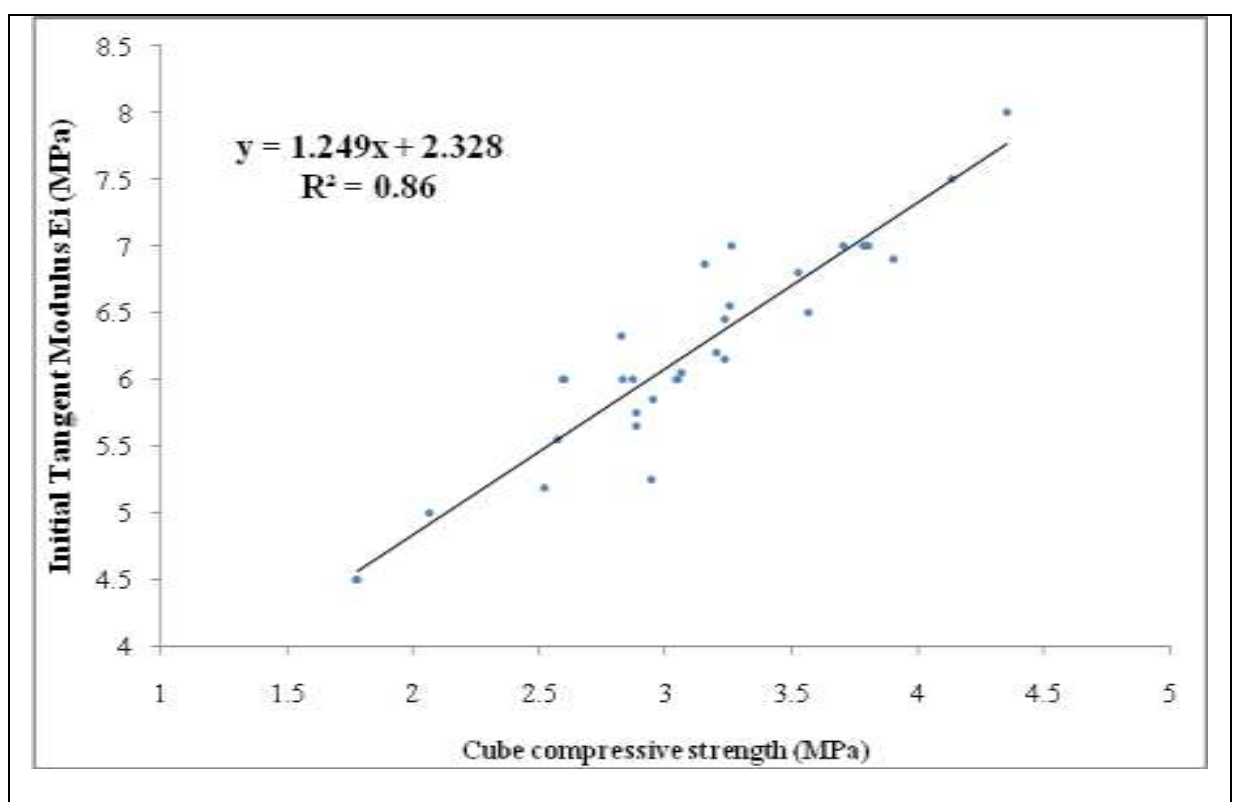

Figure 8: Relation between Initial Tangent Modulus (Ei) \& Wet Compressive Strength (sc)

\section{Conclusion}

A laboratory experimental study was performed on compressed earth blocks consisting of local non swelling soil, Demolishing waste fly ash, and cement. From the study, the following conclusions are drawn.

- In the trail experimental studies wet strength is obtained just by taking the different percentage of local soil and demolishing waste stabilised with $8 \%$ of cement of total weight of mix. The best results are obtained at 45 and $40 \%$ of soil (M4 \& M5 group). Further these groups are added with 5, 10 and $15 \%$ of FA just curtail the cement by $1 \%$ as a partial replacement of cement.

- As addition of FA increases the density up to certain extent further increase of FA reduces the density of mix and it more heterogeneous and ultimately its strength. The addition of FA up to $10-15 \%$ may suggest using in the blocks for sustainable construction.

- Demolishing waste can be effectively used in such construction as a replacement of natural sand to restrict the mining of natural material. Also recycling and reuse of such material provides the ideal solution of waste management.

- On 7 days curing, the rammed earth material can attain the wet compressive strength up to $25 \%-52 \%$ higher than those uncured material whereas on 7 to 28 days of curing the rammed earth material can gain $51 \%-73 \%$ of strength when blended with cement.

- The cube compressive strength values are in the range of 160 to $406 \mathrm{kPa}$ for 7 days curing and 200 to $435 \mathrm{kPa}$ for 28 days curing when blended with cement and FA.

- Higher compressive strength and stiffness is observed with increasing fly ash and DW and also with curing period and cement and the stress-strain curve changes from a ductile to a brittle behaviour.

- As non availability of red lateritic soil in central India, The surrounding soil can provide better solution for rammed earth construction, and can be used for load bearing structure. Earth material shows better thermal performance therefore suggested to use for low cost housing or in hot aired region which reduces the operational construction of building for entire life span of the structure.

- Use of local material reduces the cost of transportation, the manufacturing of construction material is energy intensive whereas unprocessed material save energy and also reduce carbon footprint.

\section{References}

[1]. Abhirami Suresh, et.al. (2016.),A Study on Stabilized Rammed Earth for Sustainable Construction, International Journal of Innovative Research in Science, Engineering and Technology Volume 5, Special I issue 14, pp. 303-309.

[2]. Ana Paula da Silva Milani and Lucila Chebel Labaki , "Physical, Mechanical and thermal performance of cement-stabilized rammed earth-rice husk ash wall", journal of materials in civil engineering,vol.24,no.6, june1,ASCE/JUNE 2012/775-782,

[3]. B. V. Venkatarama Reddy, et.al. (2005), Characteristics of soil-cement blocks using highly sandy Soils, Materials and Structures 38, pp.651-658.

[4]. B. V. Venkatarama Reddy, et.al.(2007),Optimum Soil Grading for the Soil-Cement Blocks ,Journal of Materials in Civil Engineering, Vol. 19, No. 2, @ASCE, pp.139-148. 
[5]. B. V. Venkatarama Reddy, Ph.D.; V. Suresh; and K. S. Nanjunda Rao, Ph.D. "Characteristic Compressive Strength of Cement-Stabilized Rammed Earth" ASCE2016

[6]. Cong Ma, et.al. (2016),Experimental Study of Effect of Fly Ash on Self-compacting Rammed Earth Construction Stabilized With Cement-based Composites, Journal of Materials in Civil Engineering, ASCE, pp. 04016022:1-10.

[7]. Cong Ma; Longzhu Chen; and Bing Chen, Ph.D., "Experimental Study of Effect of Fly Ash on SelfCompacting Rammed Earth Construction Stabilized with Cement-Based Composites" ACSE 2016.

[8]. Daniela Ciancio a, Paul Jaquin, Peter Walker, "Advances on the assessment of soil suitability for rammed earth" ,Construction and Building Materials ,42 (2013),40-47.

[9]. Deb Dulal Tripura, et.al. (2015),,Characteristic Properties of Cement-Stabilized Rammed Earth Blocks, Journal of Materials in Civil Engineering, ASCE, 0899-1561/04014214:1-8.

[10]. Deb Dulal Tripura, S.M.ASCE; and Konjengbam Darunkumar Singh2," Characteristic Properties of Cement-Stabilized Rammed Earth Blocks" ASCE 2014

[11]. Gerardo Chang Recavarren; Christine M. Fiori, M.ASCE; and Cliff Schexnayder "Rammed Earth: Construction Lessons from Experience"ACSE 2013.

[12]. Hall, $M$ and Djerbib. Y.(2004), 'Rammed Erth sample production Conteest, rcommendation and Consistency' 281-286

[13]. IS 1725-1982,(reaffirmed 1997) "Specification for soil based blocks used in general building construction".

[14]. Jaysinghe,C., Kamaldasa N., (2007), Compressive strength characteristics of Cement-Stabilized Rammed Earth Walls,Construction Building Materials,21(11),1971-1976

[15]. Heathcote, K, "Compressive strength characteristics of Cement-Stabilized Pressed Earth Blocks",19(2) Building Research and Information,(1991), 101-105

[16]. Peter Walker, et.al. (1997) Properties of some cement stabilized compressed earth blocks and mortars, Materials and Structures/Mat4riaux et Constructions, Vol. 30, November 1997, pp 545-551.

[17]. Venkatarama Reddy B. V. Jagdish,(1995), Influence of Soil Composition on Strength and durability of soil-Cement Blocks", (1995),Indian Concrete journal (69)9.

[18]. Walker, P., Strength, durability and shrinkage characteristics of cement stabilized soil blocks. Cem. Concr. Comp., 1995, 17, 301-310.

[19]. Peter Walker, Rowland Keable, Joe Martin, and Vasilios Maniatidis., "Rammed earth design and construction guidelines", BRE Bookshop Publications, UK, 2005.

[20]. Walker P. J. 2004,"Strength and erosion Characteristics of earth block and earth masonry" J. Mater. Civ. Engg.10 1061/(ASCE2004), 497-506. 